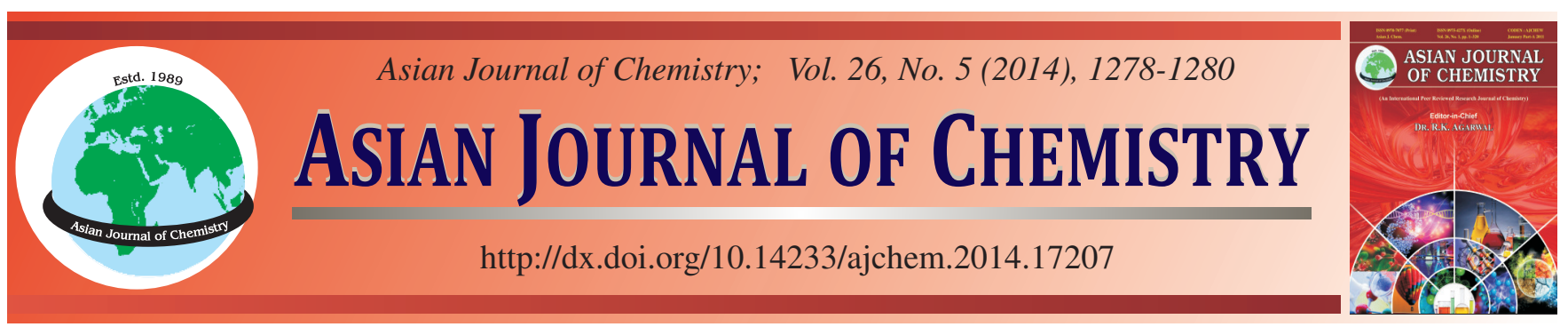

\title{
Reaction Characteristics of Blast Furnace Slag-Based Non-Cement Paste Using Alkali Accelerator and Red Mud $\dagger$
}

\author{
Sungyu Park ${ }^{1}$, Yunmi KIm² and SANGSOo LeE ${ }^{2, *}$
}

${ }^{1}$ Department of Architectural Engineering, Mokwon University, Daejeon 302-729, Republic of Korea

${ }^{2}$ Department of Architectural Engineering, Hanbat National University, Daejeon 305-719, Republic of Korea

*Corresponding author: Fax: +82 42 8211590; E-mail: sslee111@ hanbat.ac.kr

\begin{abstract}
This study involved to examine the strength properties and reactions of non-cement paste that used the blast furnace slag from steel manufacturing and red mud, the by-products. It was found that $\mathrm{KOH}, \mathrm{NaOH}$ and $\mathrm{Ca}(\mathrm{OH})_{2}$ stimulated the blast furnace slag particles and created the C-S-H (calcium silicate) hydrate, etc., resulting in the hardening of non-cement paste. The results of compressive strength test suggested that both $\mathrm{KOH}$ and $\mathrm{NaOH}$ exhibited a tendency that compressive strength decreased as the replacement rate of red mud increased. In addition, the test specimen added with $\mathrm{Ca}(\mathrm{OH})_{2}$ showed the increased strength proportionally to the replacement rate, but showed much lower strength compared to that of $\mathrm{KOH}$ and $\mathrm{NaOH}$.
\end{abstract}

Keywords: Blast furnace slag, Alkali accelerator, Red mud, SEM-EDS, Non-cement.

ᄂ - - - - - - - - - - - - - - - - - - - - - - - - -

\section{INTRODUCTION}

The manufacture and production of cement involve the use of fossil fuels, which is the main cause of $\mathrm{CO}_{2}$ generation. For example, $\mathrm{CO}_{2}$ emissions occur during the process of making cement $(\mathrm{CaO})$ with limestone $\left(\mathrm{CaCO}_{3}\right)$ and in this process, massive amount of $\mathrm{CO}_{2}$ is generated, again when fossil fuel is burned to supply the heat required in this process ${ }^{1,2}$.

One of the solutions is to produce a non-cement paste which is based on the blast furnace slag. Blast furnace slag is advantageous for long-term strength due to its latent hydraulic property, but is difficult to secure the strength of early age. Such blast furnace slag destroys and stimulates the film of blast furnace slag particles which cause latent hydraulic property by using the alkali accelerator.

However, there has been no research that concluded clearly about the compatibility based on the type of alkali accelerator and blast furnace $\operatorname{slag}^{3,4}$. Therefore, this study intended to produce the matrix based on blast furnace slag by using the $\mathrm{KOH}, \mathrm{NaOH}, \mathrm{Ca}(\mathrm{OH})_{2}$, the alkali accelerators.

\section{EXPERIMENTAL}

The blast furnace slag (BFS) used in this experiment has the density of $2.91 \mathrm{~g} / \mathrm{cm}^{3}$, fineness of $4,464 \mathrm{~cm}^{2} / \mathrm{g}$. Its chemical composition, it $\mathrm{SiO}_{2}$ and $\mathrm{CaO}$ which comprises 35.08 and $41.10 \%$, respectively. The red mud (RM) has the density of $3.37 \mathrm{~g} / \mathrm{cm}^{3}$ and fineness of $3,483 \mathrm{~cm}^{2} / \mathrm{g}$. Its chemical composition, is with $25.14 \%, \mathrm{Al}_{2} \mathrm{O}_{3}$ with $33.30 \%, \mathrm{Fe}_{2} \mathrm{O}_{3}$ and with $8.30 \%$ of $\mathrm{Na}_{2} \mathrm{O}$ the alkaline component (Table-1).

This study is conducted in order to produce the noncement paste (NCP) based on blast furnace slag. The W/B was fixed at 0.45 and the $\mathrm{KOH}, \mathrm{NaOH}, \mathrm{Ca}(\mathrm{OH})_{2}$ were used as alkali accelerator. In addition, $10 \%$ by weight of binder was added.

Furthermore, it was cured at the humidity of $80 \pm 5 \%$ and temperature of $20 \pm 2^{\circ} \mathrm{C}$ by substituting with $0,10,20,30$ (wt. \%), etc., in blast furnace slag to reduce the consumption of alkali accelerator. For the test items, scanning electronic microscope (SEM) imaging, EDS analysis were conducted and compressive strength were measured. The factor and level of this experiment are presented in Table-2.

SEM imaging and EDS analysis were conducted on the 28th day in order to observe the microstructure and chemical composition of each non-cement paste. Moreover, the test specimen was produced with $40 \mathrm{~mm} \times 40 \mathrm{~mm} \times$ $160 \mathrm{~mm}$ mold in accordance with the cement strength test method (KS L ISO 679) to measure the compressive strength by age.

†resented at The 7th International Conference on Multi-functional Materials and Applications, held on 22-24 November 2013, Anhui University of Science \& Technology, Huainan, Anhui Province, P.R. China 


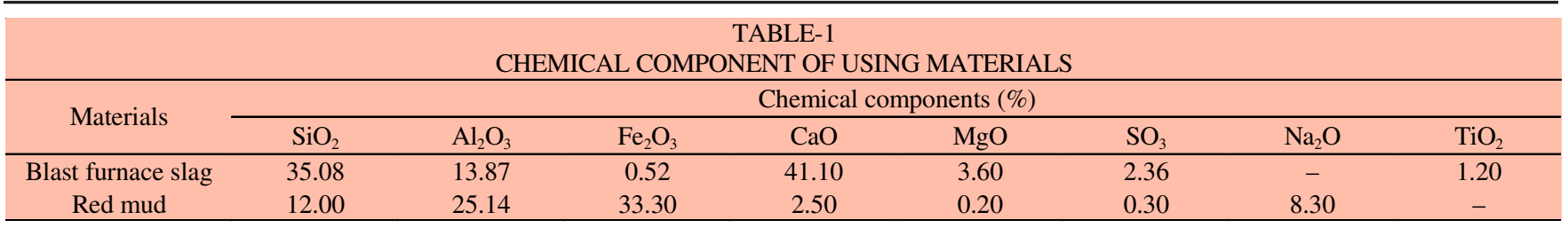

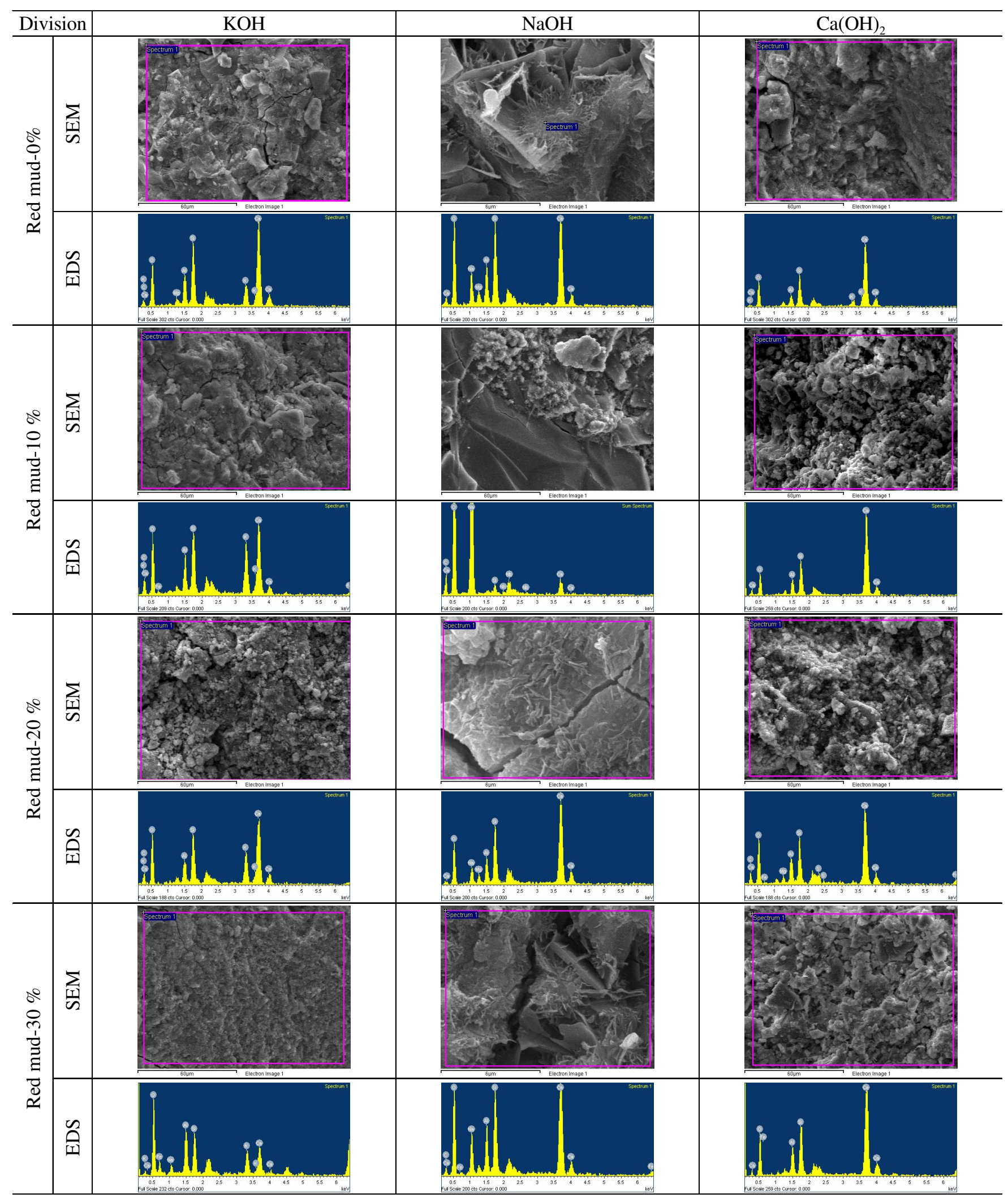

Fig. 1. SEM-EDS in the 28 days 


\begin{tabular}{lc}
\hline \multicolumn{2}{c}{ EXPERIMENTAL FACTORS AND LEVELS } \\
\hline \multicolumn{1}{c}{ Factors } & Levels \\
\hline Binder type & $\mathrm{BFS}, \mathrm{RM}$ \\
Alkali accelerator & $\mathrm{NaOH}, \mathrm{KOH}, \mathrm{Ca}(\mathrm{OH})_{2}$ \\
$\begin{array}{l}\text { Addition ratio of } \\
\text { alkali accelerator }\end{array}$ & $10(\mathrm{wt} \%)$ \\
$\begin{array}{l}\text { Replacement rate of } \\
\text { red mud }\end{array}$ & $0,10,20,30$ (wt. \%) \\
Curing condition & Relative humidity $(80 \pm 5) \%$, temp. $(20 \pm 2)^{\circ} \mathrm{C}$ \\
W/B & 0.45 \\
Test items & SEM-EDS, XRD, compressive strength \\
\hline
\end{tabular}

\section{RESULTS AND DISCUSSION}

SEM-EDS: The results of SEM imaging and EDS analysis suggested that the glassy film of BFS particles were destroyed by $\mathrm{KOH}, \mathrm{NaOH}, \mathrm{Ca}(\mathrm{OH})_{2}$, the alkali accelerators, leading to the elution of the components necessary for hydration reaction, such as $\mathrm{SiO}_{2}, \mathrm{CaO}$, which were contained in BFS particle and resultantly, BFS-based NCP was hardened (Fig. 1).

For the $\mathrm{NCP}$ added with $\mathrm{KOH}$, there was a slight difference in size and compactness, depending on the replacement rate of red mud. However, all NCPs massed and microcrack was observed between the crystals. That is attributed to the fact that the expandable hydrated product was created by $\mathrm{K}^{+}$, although the strength would be increased by the formation of compact structure as a result of reaction through $\mathrm{KOH}$ between water and components that were contained in BFS.

The NCP added with $\mathrm{NaOH}$ also formed the compact structure in the same way as when the $\mathrm{KOH}$ was added. The 2-dimensional netlike C-S-H hydrate was observed in the test specimen that did not substitute the red mud.

Furthermore, the test specimen that substituted the 20 and $30 \%$ showed the layered product and $\mathrm{Na}$ phase which were different from those of the test specimen that did not substitute the red mud. Microcrack was observed in the surface of test specimen.

Massiveness similar to that of $\mathrm{KOH}$ was observed in NCP which was added with $\mathrm{Ca}(\mathrm{OH})_{2}$. However, there was no formation of the structure with compactness greater that of the test specimen which had been added with $\mathrm{KOH}$. The low reactivity of $\mathrm{Ca}(\mathrm{OH})_{2}$ prevented the complete hardening of the material even in the 28 days and therefore, long-term observation would be necessary.

Compressive strength: The results of compressive strength test showed that the compressive strength diminished in the test specimen added with both $\mathrm{KOH}$ and $\mathrm{NaOH}$ as the replacement rate of red mud increased. For the NCP added with $\mathrm{KOH}$ and $\mathrm{NaOH}$, the test specimen that did not substitute the red mud exhibited the highest strength in the 28th day. The NCP added with $\mathrm{KO}$ and $\mathrm{NaO}$ showed the decreasing strength as the replacement rate of red mud increased. That is considered to be attributable to the crack caused by red mud.

Besides, the substitution of red mud resulted in the reduction of the amount of BFS that plays a key role in the strength development and furthermore, all alkaline components required for activation of BFS were supplied from the alkali accelerator prior to the elution of $\mathrm{Na}_{2} \mathrm{O}$ contained in red mud.
Therefore, the $\mathrm{Na}^{+}$in red mud which was not involved in hydration reaction remained inside the test specimen and became a factor that decreased the strength over the long-term.

Meanwhile, the NCP test specimen added with $\mathrm{Ca}(\mathrm{OH})_{2}$ showed the increased strength as the replacement rate increased, but exhibited noticeably lower strength compared to that of $\mathrm{KOH}$ and $\mathrm{NaOH}$. That is attributed to low reactivity of $\mathrm{Ca}(\mathrm{OH})_{2}$, leading to the lower strength compared to NCP which used the $\mathrm{KOH}$ and $\mathrm{NaOH}$, as it was mentioned about the results of SEM imaging. As a result, the $\mathrm{Na}^{+}$contained in red mud was consumed to activate the BFS and therefore, the strength increased, depending on the replacement rate of red mud (Fig. 2).

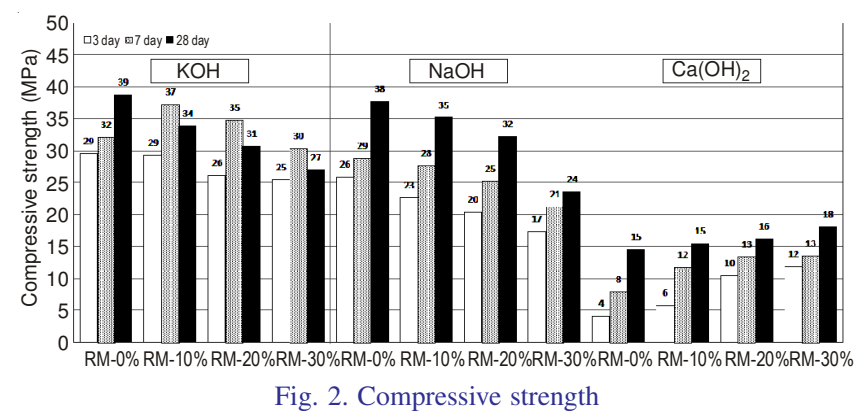

\section{Conclusion}

In this study, an experiment was conducted to produce the matrix based on the blast furnace slag by using the BFS, $\mathrm{KOH}, \mathrm{NaOH}, \mathrm{Ca}(\mathrm{OH})_{2}$ which are the alkaline accelerator and red mud which contains the alkaline component and the following conclusion was reached: All of the $\mathrm{KOH}, \mathrm{NaOH}$, $\mathrm{Ca}(\mathrm{OH})_{2}$, the alkali accelerators used in this experiment, destroyed the film of BFS particles, leading to the elution of components that were contained in BFS, thus stimulating the hydration reaction. C-S-H hydrate was found to have been formed in NCP. NCP which used both $\mathrm{KOH}$ and $\mathrm{NaOH}$ showed the decreasing strength as the replacement rate of red mud increased. Meanwhile, $\mathrm{Ca}(\mathrm{OH})_{2}$ exhibited the increasing strength, but the strength was significantly low. Thus, it is considered that red mud may replace the alkali accelerator if the consumption of both $\mathrm{KOH}$ and $\mathrm{NaOH}$ is reduced, as well as $\mathrm{Ca}(\mathrm{OH})_{2}$ and proper amount of red mud is used.

\section{ACKNOWLEDGEMENTS}

This research was supported by a grant (12 High-tech Urban D01) from High-tech Urban Development Program funded by Ministry of Land, Transport and Maritime Affairs of Korean Government.

\section{REFERENCES}

1. Korea Energy Management Corporation, "2013 Handbook of Energy", (2013).

2. E. Hyun, Master's thesis, A study on the reducing of $\mathrm{CO}_{2}$ emission from operation of environmentally friendly building, KonKuk University, Seoul, Korea, pp. 21-25 (2010).

3. S.-L. Jeong, K.-M. Cho and C.-T. Hyun, J. Korea Institute Build. Constr, 10, 73 (2010).

4. S. Lee, W. Kim and S. Kang, Magaz. Korea Concrete Institute, 24, 31 (2012). 